\title{
First generation college students and non-first-generation college students: Perceptions of belonging
}

\author{
Margaret Costello*1, Amy Ballin ${ }^{2}$, Miriam Rosalyn Diamond ${ }^{3}$, Lan Gao ${ }^{4}$ \\ ${ }^{1}$ Department of Nursing, Simmons University, Boston, Ma, United States \\ ${ }^{2}$ Department of Education, Simmons University, Boston, Ma, United States \\ ${ }^{3}$ Center for Excellence in Teaching, Simmons University, Boston, Ma, United States \\ ${ }^{4}$ Office of the Provost, Simmons University, Boston, Ma, United States
}

Received: May 20, 2018

DOI: $10.5430 /$ jnep.v8n12p58
Accepted: July 23, 2018

Online Published: August 8, 2018

\begin{abstract}
Background and objective: First generation college students (FGS), are emerging as an important demographic group for colleges and universities. Having a 'sense of belonging' or belonging is important to the success of all college students, especially for the retention of students who may be at risk of not completing their academic degree. The purpose of this study is to analyze differences between first generation and non-first-generation college students based on a mattering survey.

Methods: Two hundred and thirty undergraduate students in one New England College participated in a study designed to uncover differences between FGS and non-first-generation college students based on responses to a mattering survey. The study utilized a questionnaire designed to capture students' opinions on mattering. Open questions were included to inform and enrich the data.

Results: First-generation student perceived a greater number of obstacles in their college experience than non-first-generation students. Obstacles to academic success for first generation students included lack of time to study due to work and family responsibilities, financial struggles, and unhelpful faculty relationships. Facilitators were helpful faculty and peer relationships. Lack of mental health support was cited as a barrier to both cohorts of students.

Conclusions: Having a sense of belonging or mattering can help the student feel a connection to the college. This may aid the student in persisting towards graduation. Persistence toward graduation is important for all students including nursing students.
\end{abstract}

Key Words: First generation college students, First generation nursing college students, Belonging, Mattering, Obstacles to academic success

\section{INTRODUCTION}

The American Association of Colleges of Nursing (AACN) has provided a position statement in support of the recruitment of a diverse and inclusive nursing student body. ${ }^{[1]}$ able for the development of a nursing workforce able to provide high quality, culturally appropriate health care. The recruitment of diverse learners will require faculty to utilize a variety of techniques to support students. ${ }^{[1]}$

AACN recognizes diversity, inclusion, and equity is valu-

${ }^{*}$ Correspondence: Margaret Costello; Email: margaret.costello@ simmons.edu; Address: Department of Nursing, Simmons University, Boston, Ma, United States. 
First generation college students (FGS), a growing population in the United States, are emerging as an important demographic group for all colleges and universities. First generation college students account for over $50 \%$ of undergraduates in the United States. ${ }^{[2]}$ A review of the literature by Peralta $\&$ Klonowski ${ }^{[3]}$ revealed differences in how first generation students are defined. These definitions include students whose parents had some college coursework but did not complete a college degree; students whose parents never attended college. There is no standard definition of the first-generation college student. This study considers the FGS a student whose parent never attended college. We selected this definition because it is the definition utilized by the university that is the setting for the study.

In 2016, approximately $18.8 \%$ of incoming students identify as first generation college students. ${ }^{[4]}$ Data on first generation nursing students is not reported. When compared with students whose parents attended college, first generation students complete fewer credits and are more likely to withdraw from or repeat courses they attempt. First generation students are also less likely to complete a baccalaureate degree than students with parents who attended college. ${ }^{[5]}$ Since student retention is a major educational and financial concern for academic administrators, examination of the factors that contribute to the decrease in retention is indicated. ${ }^{[6]}$ According to Hausmann Schofield, \& Woods, ${ }^{[7]}$ the greater the sense of belonging to the institution, the more likely it is that the student will remain in college.

As nursing educators, we are called on to develop strategies to best support a diverse group of students. ${ }^{[8]}$ Retaining students following acceptance into the nursing program is crucial to the development of the nursing workforce. ${ }^{[8]}$ A study which examined barriers to academic success during the first year of nursing program uncovered that the combination of first generation status and lower income was associated with decreased academic success. Of the 1,238 students identified as both low income and first generation, 52\% passed their respective courses compared to $75 \%$ of first generation students whose gross income exceeded $\$ 25,000 .^{[9]}$

As the American population grows older and nurses increasingly near retirement age, the need for registered nurses is increasing. ${ }^{[10]}$ Results of a national study found a sense of belonging to have positive influence and impact on nursing students' learning, motivation and confidence. ${ }^{[11]}$ The same study identified a statistically significant low inverse relationship between a sense of belonging and perceived stress among baccalaureate nursing students in their clinical placements. Having a sense of belonging has been found to contribute to a student's retention in a college or univer- sity. Yet many FGS do not have that sense of belonging. ${ }^{[12]}$

Researchers found that feelings of belonging are also significantly related to mental health concerns among students. ${ }^{[12]}$ First generation students report a higher frequency of feeling stressed, depressed, or upset compared with non-firstgeneration students. ${ }^{[12]}$ For students who are not as engaged in the college experience, life at college can be isolating. ${ }^{[13]}$

The extent to which students feel that they belong in the academic environment positively affected the degree to which they viewed themselves as capable students. ${ }^{[14]}$ Students with a strong sense of belonging in an educational institution also see themselves as being capable of greater success in that environment with a greater sense of self as a successful student. ${ }^{[14]}$ Students who develop a sense of belonging on campus successfully connect with the college environment. Feeling as though one is an important part of their college environment is especially helpful to first year college students as they negotiate their new campus. ${ }^{[13]}$ Research conducted on the college student experience of their sense of belonging suggests there is a strong relationship between belonging, student retention, and graduation. ${ }^{[15]}$

Having a sense of belonging gives rise to feelings of mattering. ${ }^{[16]}$ Perceived Mattering (PM) is defined as "the psychological tendency to evaluate the self as significant to specific other people."[17] This concept suggests that individuals develop a sense of PM in their relationships based on the quality of the interactions. ${ }^{[17]}$ Perceived Mattering in the relationships has been linked to feelings of individual well-being. ${ }^{[18]}$ Marginality is the perception that one does not fit in, is not significant, and is not needed. ${ }^{[18]}$ Schlossberg ${ }^{[19]}$ noted that when college students believe that they matter to others, their feelings of marginality diminish; college students succeed in a multitude of ways when they perceive that they are appreciated by others and receive positive affirmation. ${ }^{[20]}$

A review of the literature reveals a dearth of studies examining the relationship between perceived mattering and student nurses. In his qualitative research study, Hutchins, R. S. ${ }^{[21]}$ found that nursing students who had failed a nursing course, exhibited loss of self-confidence due to a sense of marginalization which was found to have contributed to academic failure. Students' ability to overcome the loss of confidence following a nursing course failure contributed to the respondent's belief that he/she mattered. ${ }^{[21]}$

The purpose of this study is to uncover differences between FGS and non-first-generation college students in terms of belonging. The study aims to understand how FGS and nonfirst-generation students describe the feeling of mattering during their first year of college. 


\section{MeThODS}

The setting for this study was a small private urban university in the Northeast United States in 2017. Approximately 1,801 undergraduates attend the university, where nursing is its largest major. Four hundred first year students are enrolled each year with 75 of these being undergraduate nursing students. Institutional review board (IRB) approval was obtained through the University Office of Sponsored Programs.

A purposive sample drawn from all first, second, and third year undergraduate students was obtained. One thousand two hundred and two $(1,202)$ students were invited to participate in the study via email. The email included a brief description of the survey and included details about the confidential and voluntary aspects of the survey. Incentives for students to participate in the survey included enrollment in a raffle with 6 possible monetary prizes. Students who agreed to participate in the study were given an email link for the Student Mattering Survey, utilizing Qualtrics software in Spring 2017.

Data collection occurred in two ways. The first was the Student Mattering Survey, developed by Diamond ${ }^{[22]}$ based on the work of Schlossberg, ${ }^{[19]}$ and Pascarella. ${ }^{[23]}$ The survey has two sections: college climate and obstacles. The college climate questions focused on students' overall perceptions of the college. The obstacle section has 5 subscales which include questions on the following topics: academic, employment, financial, personal circumstances, and campus climate. Internal reliability data from the original survey reveals Cronbach values ranging from .77 to $.86 .{ }^{[22]}$ The Cronbach value of the revised tool was .68. Quantitative survey data was analyzed utilizing SPSS. Chi square tests for difference between first generation and non-first-generation students were conducted.

Open-ended questions were included in the study. These questions were: "Describe a time when you felt you mattered to people (classmates, faculty, staff) at the college. What happened? What made you feel you mattered? How did the experience affect your feelings about attending college?" These qualitative questions were designed to gain a deeper understanding of the first-year experience by enriching the data being analyzed with the inclusion of students' personal reflections on when they did or did not matter in their initiation into college life. The student responses were coded by two trained researchers using thematic analysis. Thematic analysis was utilized as it was deemed the best approach to analyze and develop themes based on texts. ${ }^{[24]}$ Two researchers sorted and coded the qualitative data individually and together. Our process involved reading the student responses twice and becoming very familiar with the data. We separately generated initial codes then obtained the emerging themes. Together we reviewed and further defined the themes.

\section{RESUlts}

Two hundred and thirty students participated in the study. Seventy-one percent (53) were undergraduate nursing students, twenty-one percent (11) of the nursing students were first generation students. From the total sample, twenty-one percent (49) self-selected first-generation status based on the definition which was provided in the survey. Of the FGS, the demographics include: 37 (18\%) white, 12 (24\%) Asian, 4 (8\%) Black or African American, 2 (6\%) Hispanic, 2 (6\%) international students.

The first section of the survey included general climate questions. These questions sought to explore students' feelings about the college in general. Questions in Table 1 were not significant for non FGS. First generation students indicated that rules were not clear to them and that campus rules and regulations appeared to be made for students whose parents went to college. First generation students also indicated that they had fewer opportunities to get to know students and that classmates did not help them catch up on technologies. There were no statistically significant differences between feelings of loneliness and isolation between the FGS and non FGS. Both groups of students also reported that at times they felt unwelcome at the college.

The obstacle category proved to contain the most statistically significant data differentiating the first generation from the non-first-generation students and it is reported below.

Table 1. Climate questions

\begin{tabular}{ll}
\hline Please indicate the response which best describes how you feel at the college & $\boldsymbol{p}$ value \\
\hline The administrative rules and regulations are clear to me. & $\leq .01$ \\
My classmates help me catch up to the technologies if I need it. & $\leq .05$ \\
I have had adequate opportunities to get to know students. & $\leq .05$ \\
Campus rules and regulations seem to have been made for students whose parents went to college. & $\leq .05$ \\
\hline
\end{tabular}




\subsection{Academic}

This domain includes obstacles related to areas of study including completion of assignments. Both non-firstgeneration and FGS provided similar responses about the challenging nature of the coursework. However, inadequate study habits, low grades, and difficulty of courses were significant obstacles for the first generation students $(p<.05)$. First generation students reported that the time needed for studying was a significant obstacle $(p<.05)$.

\subsection{Employment}

This area concerned managing work and school simultaneously. First generation college students typically work longer hours, more often work off campus, and have a longer commutes to their place of employment. First generation college students more frequently reported that they were planning to get a new job or join the military than their non-firstgeneration peers $(p<.05)$. Employment scheduling conflicts are a significant area of concerns for FGS. First generation college students indicated greater difficulty securing a job with hours that support their school hours $(p<.05)$. The firstgeneration students who did have a job report more conflicts between work and studies than non-first-generation students $(p<.001)$.

\subsection{Financial}

This category dealt with financial barriers concerning college education. First generation students, with greater frequency than non-first-generation students, considered the high cost of their education to be a significant obstacle. First generation students more often than non-first-generation students applied and did not receive any financial aid. When financial aid was received, it was insufficient. First generation stu- dents also reported that insufficient funds were a significant obstacle to continuing their education was $p<.01$.

\subsection{Personal circumstances}

These questions dealt a variety of personal circumstances related to health of self or family members and children. More FGS reported interfering personal circumstances such as family obligations or health issues, which created barriers to their educational pursuit $(p<.001)$. A significant number of FGS had a greater number of family responsibilities than non-first-degree students $(p<.001)$. First generation students also reported going home to visit their family more often ( $p$ $<.001)$.

\subsection{Campus climate}

Climate questions related to students' sense of belonging or connection. First generation students were more likely to report that faculty were not accessible than their non-firstgeneration peers. First generations students reported feeling isolated and having difficulty meeting people was a significant obstacle. They also indicated that they felt they did not belong at the college and that they had no sense of community and that there is a lack of support for FGS on campus ( $p$ $<.0001)$.

Table 2 highlights the significant findings between first gen and non-first gen.

The qualitative analysis generated common themes for both FGS and non-first-generation students. These included helpful faculty, recognition of their ability/skill, and friendships as important to mattering. Students felt support and recognition by faculty made a difference to their sense of belong to the school community.

Table 2. Obstacle findings

\begin{tabular}{lll}
\hline & Please indicate the extent each does or does not affect your studies & $\boldsymbol{p}$ value \\
\hline & Low grades & $\leq .05$ \\
Academic & Inadequate study techniques or habits & $\leq .001$ \\
& Courses difficult & $\leq .05$ \\
& Scheduling conflicts between work and studies & $\leq 0.01$ \\
Employment & New job/entering military & $\leq .05$ \\
& Unable to find a job that matches school hours & $\leq .05$ \\
Financial & Not enough money to continue & $\leq .01$ \\
& Personal problems & $\leq .001$ \\
Personal Circumstances & Studying too time-consuming & $\leq .05$ \\
Campus Climate & Family responsibilities too great & $\leq .001$ \\
\hline
\end{tabular}




\subsection{Helpful supportive faculty}

The most prevalent theme from the comments was helpful and supportive faculty. Both FGS and non FGS described the importance of the role faculty can play in making them feel that they matter. For example:

FGS: "I had begun struggling in one of my courses, and my professor reached out to me personally expressing his concern."

Non FGS "I felt like I mattered when my teacher reached out to me after a few absences to check that I was OK."

\subsection{Recognition by others}

The second major theme extracted from the student comments was feeling that they mattered when they experienced recognition by someone in the academic community. This could be a fellow student, administrator, or faculty. Sample comments were:

FGS: "being asked to speak at an event." Non FGS "I was asked to be featured as student of the month."

\subsection{Supportive peers}

The third theme we arrived at was the effect of supportive peers. First generation and non-first-generation students described how supportive friendships made them feel that they mattered in college.

Non FGS "My friends here at the college always make me feel like I matter. They are responsive to my problems and are a good support system."

FGS "This semester I went through some tough moments in my personal life and I feel very supported by my friends."

The responses also revealed differences between the FGS and non-FGS. Non-first-generation students described additional times when they felt that they mattered which were not expressed by the first-generation students. These included: sense of community, helping others/meaningful jobs and roles, clubs/activities/sports (outside class).

\subsection{Sense of community}

A common theme found among non-first-generation students was the sense of community. Non-first-generation students described feeling that they mattered when they felt a sense of community. A subtheme of this theme included involvement in athletics, clubs and other activities.

Non FGS "During hall activities or hanging out in the lounge, sometimes people talk to each other and it looks like a community of peers."

\subsection{Clubs/activities/sports (outside class)}

Non FGS "I felt like I mattered when I was on hall council."

\subsection{Helping others/meaningful jobs and roles}

The non-first-generation students also described feeling that they mattered when they were helping others. These helpful moments included times when they were being a tutor or volunteering.

Non FGS "Being a tutor makes me feel that I matter; being an ambassador makes me feel like I matter."

When answering the questions "Can you think of a time when you did not matter?" Similar themes emerged from both nonfirst gen and first-generation students. These themes included the non-helpful/un supportive faculty, and lack of friendships and perceived lack of support around disabilities especially mental health issues.

\subsection{Lack of support around disabilities especially men- tal health issues}

Both FGS and non FGS described feeling that they did not matter when issues related to their mental health are not taken seriously by faculty or college administrators.

FGS: "I had an experience where I went to a professor about presenting in class and my major anxiety with it, and they were very ignorant of the subject matter, as if anxiety does not exist and my feelings were irrelevant. It made me start to think if the faculty at the college truly cared about their students or not".

Non FGS "When applying for disability services, I felt that the college, did not want to help me at all. The people in the office gave me confusing and conflicting information, did not respond to me in a timely manner and failed to validate my concerns."

In addition to the above situations which led to students feeling that they did not matter, FGS reported feeling unsupported by the financial aid office at significantly greater proportion than non-first-generation students.

\subsection{Lack of support around financial issues}

FGS "I went to the financial office to talk to my financial advisor to find out if there were different ways I could pay for a summer course. She wasn't very helpful and didn't seem that she was willing to help me get the hep I needed. I felt like I wasn't being treated fairly ... I felt like I was left to figure everything out on my own. as a foreign student, it can be difficult to get financial aid, so I really felt horrible that day and struggled to work 2-3 jobs so that I never have to go to that office again." 


\section{Discussion}

The quantitative data indicated that first generation students had more obstacles to completing their education than did non-first-generation students. Overwhelmingly FGS in our study reported that they experienced academic challenges. Some of these issues evolved around a need for more time to study yet this is complicated by a need to maintain outside employment to address well documented financial concerns affecting many FGS. ${ }^{[2]}$ The FGS in our study indicated that personal circumstances such as family obligations, financial limitations and work responsibilities were significant issues. The findings of our study confirmed previous research showing that first-generation college students have academic and social differences from non FGS that are exacerbated by work and family responsibilities and financial struggle. ${ }^{[25]}$ First-generation students often report having less time for academic work than non-FGS. ${ }^{[26]}$

The survey also revealed that FGS did not feel they had adequate opportunities to get to know other students. Not knowing peers may contribute to FGS finding that classmates are not available to help them to catch up with technologies. Both FGS and non FGS in our study indicate that friendship is an important factor in students' sense of mattering. Previous research indicates that students' friendship support is a powerful predictor of mattering. ${ }^{[8,27]}$ Additionally, the support college students receive from friends is a significant factor in alleviating student's feelings of loneliness. ${ }^{[28]}$ It is interesting that in our study both groups of students experienced loneliness and isolation; however, what distinguished these feelings with the FGS is that they reported them to be a significant barrier to their success.

Non-first-generation students in our study reported that they felt a sense of connection and belonging when they are helping others. However, this was not a significant finding with our first generation students. Previous research did report on the positive effect of being in a helpful role. It is unclear if this is because FGS in our study truly do not experience an increased sense of belonging through being in helpful roles or that they may lack opportunity or time to volunteer due to financial constraint. This may be because the non FGS had more activities that provided them with fulfillment such as extracurricular activities that the non FGS did not seem to participate in such as helping others, /meaningful jobs and roles, clubs/activities/sports outside class. In our study, this theme was not found with the FGS. One possible explanation for this finding may be that the first generation students, due to time constraints or financial/work obligations do not have time to participate in extracurricular activities. First-generation students felt they had inadequate opportunities to meet other students. This is consistent with

Published by Sciedu Press studies which support that being a mentor to others or being helpful and supportive is beneficial to the helper. ${ }^{[29]} \mathrm{A}$ study of high achieving FGS found that the students benefited from extracurricular involvement in on-campus student organizations, community service projects, and time intensive internships in their respective fields. ${ }^{[30]}$

The qualitative questions showed that both FGS and non-first generation student found similar themes that contributed to their sense of mattering such as helpful faculty, recognition by others, and helpful peers contributed to their sense of mattering. This is consistent with previous research that indicates that participation in activities which foster connections with peers and faculty have been associated with increased perception of student support and improved perception of the college environment. ${ }^{[31]}$ Student-faculty relationships have been shown to positively influence students both academically and emotionally. ${ }^{[32]}$

An unexpected finding by both cohorts of students was that they felt their disability needs were not addressed, particularly mental health needs. This may be due to the increase in students with disabilities attending college. It's been reported that one in seven students have at least one chronic disability and one in eight students report having significant depression. A 2016 survey of incoming first-time, full-time college students found $11.9 \%$ reported feeling depressed with great frequency in the past year and $34.5 \%$ frequently felt anxious. ${ }^{[4]}$ The overwhelming comments by both first generation and non-first generation concerning lack of support around mental health issues was an unexpected finding, though one that is not surprising given the high incidence of student reports of depression and anxiety. ${ }^{[4]}$ Interestingly, both cohorts of students felt that their disability needs not being addressed left them feeling that they did not matter. This is consistent with a research study that examined the concept of belonging and mental health by surveying $145,150 \mathrm{stu}-$ dents across six large public research institutions. ${ }^{[20]}$ Their findings indicated that all college students felt that their mental health needs were not adequately addressed and that the sense of belonging is significantly related to mental health. In their study FGS reported more depression and anxiety symptoms and a decreased sense of mattering and belonging students have a higher compared with non-first-generation students. ${ }^{[20]}$

\subsection{Limitations}

A major limitation of the project concerned the sample size and characteristics. This project was limited to one small baccalaureate program in a private university in the Northeast, United States. Additionally, the college is woman centered. Thus, the results of the project are not generalizable to the 
larger population of undergraduate students.

\subsection{Implications}

Research indicates that the greater the sense of belonging or mattering to the academic and social community for the student, the more likely it is that the student will persist toward graduation. ${ }^{[7]}$ Developing a 'sense of belonging' is important to the success of all college students, especially for the retention of students who may be at risk of not completing their academic degree. ${ }^{[33]}$ Data on changing United States (US) demographics and an aging nursing workforce suggest that more nurses will be needed to meet the needs of the US population. ${ }^{[10]}$ Creating an inclusive academic environment that supports the retention and graduation of newly licensed nurses is the responsibility of nurse educators. ${ }^{[34]}$

Faculty and peers have a significant role in helping FGS feel like they matter. Faculty accessibility is important to students. Reaching out often with a willingness to connect may have the effect of letting student feel that they matter. Also, the development of classroom techniques designed to have students work together may foster peer relationship building in the classroom. Faculty can address these needs by having open dialogue with students and creating a safe place for them to voice their concerns. Flexibility around academic assignment deadlines may ease some of the stress students experience. Future research into the role of faculty specifically aimed at uncovering the best practices to support FGS is recommended as a next step. Peer and/or faculty mentors may provide additional support for FGS.

The development of paid opportunities for FGS to serve in helping roles such as ambassadors, tutors, or peer mentors may be helpful. Through faculty and peer mentorship specifically designed to provide support, FGS may develop a sense of belonging in the academic setting. A pilot which would include educating faculty on the issues specific to FGS would be a great next step in assessing the effectiveness of these mentorship roles toward helping with improving first generation students' sense of perceived mattering belonging and decreasing attrition rates during the crucial first year.

The finding of lack of support around disability issues espe- cially those related to mental health certainly deserves further investigation. Research design to uncover interventions that will best help support students who are facing mental health challenges is warranted. Classroom sensitivity on the part of faculty about students concerns related to anxiety and depression is important and should not be dismissed.

College expenses are a concern for all college students, and students, however students in our study indicated that financial concerns are a major barrier to continuing college. Administration must address these financial concerns as it is a key factor in retention for this population. Responsible caring practices designed to help the FGS succeed are crucial to the retention of a diverse student population.

\section{Conclusion}

First year college students entering a new life chapter face numerous unfamiliar experiences which may at times present challenges. These challenges may be especially overwhelming for the first-generation student who perceive greater number of obstacles. These obstacles can interfere with their ability to adapt to the college environment. Having a sense of belonging or mattering can help the student feel a connection to the college. This may aid the student in persisting towards graduation. Persistence toward graduation is important for all students and has been seen as especially valuable for nursing students. Nursing faculty and college administrators play a key role in supporting students during the crucial first year by having an awareness of the obstacles FGS face and their role in facilitating the students' experience. Students thrive in an environment which is supportive and caring. Faculty can support students by facilitating supportive relationships and teaching practices. The recruitment of diverse learners such as FGS will require faculty to utilize a variety of techniques to support students. Students thrive in an environment where they feel they belong. Faculty have an important role in supporting students by feelings that they matter or belong in the academic environment.

\section{Conflicts of InTEREST Disclosure}

The authors declare that there is no conflict of interest.

\section{REFERENCES}

[1] AACN: Diversity, inclusion, and equity in academic nursing. Washington, DC: American Association of Colleges of Nursing; 2017 Available from: http://www.aacnnursing.org/News-Infor mation/Position-Statements-White-Papers/Diversity

[2] Davis J. The first-generation student experience implications for campus practice, and strategies for improving persistence and success.
Sterling, Va: Stylus; 2010.

[3] Peralta KJ, Klonowski M. Examining conceptual and operational definitions of "first-generation college student" in research on retention. J Coll Stud Dev. 2017; 58(4): 630-636. https://doi.org/10.1 353/csd.2017.0048

[4] Eagan K, Stolzenberg E, Zimmerman H, et al. The American freshman: national norms fall 2016 [Internet]. Higher Education Research 
Institute. 2017; Available from: https://www.heri.ucla.edu/ monographs/TheAmericanFreshman2016.pdf

[5] Redford J, Hoyer K, Ralph J. First-generation and continuinggeneration college students: a comparison of high school and postsecondary experiences national center for education statistics [Internet]. 2017. Available from: https://nces.ed.gov/pubsearch/pubs info. asp?pubid=2018009

[6] Yao C, Kang Z. Retention and student success: A study of first time full time FGS at UNC Pembroke. In S. Whalen (Ed.), Proceedings of the 13th National Symposium on Student Retention. Destin Florida. Norman OK: The University of Oklahoma. 2017.

[7] Hausmann L, Schofield J, Woods R. Sense of belonging as a predictor of intentions to persist among African American and white first-generation students. Research in Higher Education. 2007; (7): 803.

[8] Huerta AH, Fishman SM. Marginality and mattering: urban latino male undergraduates in higher education. Journal of the First-Year Experience and Students in Transition. 2014; 26(1): 85-100.

[9] Ott V, Thomas JA, Fernando H. First-year success in a nursing baccalaureate plan of study: A descriptive research study. Nurse Educ Today. 2018; 67: 108-113. PMid:29857303 https://doi .org/10 $.1016 / j$.nedt .2018 .05 .005

[10] AACN: Nursing shortage: fact sheet. [Internet]. Washington, DC: American Association of Colleges of Nursing; c2017. Available from. http://www . aacnnursing.org/Portals/42/News/ Factsheets/Nursing-Shortage-Factsheet-2017.pdf

[11] Grobecker PA. A sense of belonging and perceived stress among baccalaureate nursing students in clinical placements. Nurse Educ Today. 2016; 36: 178-183. PMid:26471423 https ://doi .org/10 $.1016 / j$.nedt .2015 .09 .015

[12] Stebleton MJ, Soria KM, Huesman RL. First-generation students' sense of belonging, mental health, and use of counseling services at public research universities. Journal of College Counseling. 2014; 17(1): 6-20. https://doi.org/10.1002/j.2161-1882.2014 $.00044 . \mathrm{x}$

[13] Tinto, V. Reflections on student persistence. Student Success. 2017; 8(2): 1. https://doi.org/10.5204/ssj.v8i2.376

[14] Curtin N, Stewart AJ, Ostrove JM. Fostering academic self-concept: advisor support and sense of belonging among international and domestic graduate students. American Educational Research Journal. 2013; 50(1): 108-137. https://doi.org/10.3102/0002831212 446662

[15] Tovar E, Simon MA, Lee HB. Development and validation of the college mattering inventory with diverse urban college students. Meas Eval Couns Dev. 2009; 42(3): 154-178. https://doi.org/10.1 $177 / 0748175609344091$

[16] Taylor J, Turner RJ. A longitudinal study of the role and significance of mattering to others for depressive symptoms. J Health Soc Behav. 2001; 42(3): 310-325. https://doi .org/10.2307/3090217

[17] Marshall SK. Do I matter? Construct validation of adolescents' perceived mattering to parents and friends. J Adolesc. 2001; 24: 473-490. PMid:11549327
[18] Rosenberg M, McCullough BC. Mattering: inferred significance to parents and mental health among adolescents. Res Community Ment Health. 1981; 2: 163-182.

[19] Schlossberg NK. Marginality and mattering: key issues in building community. New Directions for Student Services. 1989; 48: 5-15. https://doi.org/10.1002/ss.37119894803

[20] Stebleton MJ, Huesman RL, Kuzhabekova A. Do I belong? Exploring immigrant college student responses on the SERU survey sense of belonging/satisfaction factor. CSHE. 2010.

[21] Hutchins RS. The concept of mattering as critical to nursing-student recovery [dissertation]. Eastern Michigan University; 2017. 77 p.

[22] Diamond MR. Does it matter to matter? The role of involvement and mattering for returning adult undergraduate students [dissertation] [(Ann Arbor, MI)]: University of Michigan; 1995.

[23] Pascarella ET, Chapman DW. Validation of a theoretical model of college withdrawal: Interaction effects in a multi-institutional sample. Research in Higher Education. 1982; 19(1): 25-48.

[24] Braun V, Clarke V. Using thematic analysis in psychology. Qual Res Psychol. 2006; 3(2): 77-101. https://doi.org/10.1191/1478 088706qp063oa

[25] Engle J, Tinto V, Pell Institute. Moving beyond access: college success for low-income, first-generation students. Pell Institute for the Study of Opportunity In Higher Education. 2008 Feb. 38 p.

[26] Katrevich AV, Aruguete MS. Recognizing challenges and predicting success in first-generation university students. J STEM Educ. 2017; 18(2): 40-44

[27] Rayle AD, Chung K. Revisiting first-year college students' mattering: social support, academic stress, and the mattering experience. J Coll Stud Ret. 2008; 9(1): 21-37.

[28] Lee C, Goldstein S. Loneliness, stress, and social support in young adulthood: does the source of support matter? J Youth Adolesc. 2016; 45(3): 568-580. PMid:26602564 https://doi.org/10.1007/s1 0964-015-0395-9

[29] Brown S. Providing social support may be more beneficial than receiving it: results from a prospective study of morality. Psychological Science. 2004; 4(14): 320-327.

[30] Hébert TP. An examination of high-achieving first-generation college students from low-income backgrounds. Gift Child Q. 2018; 62(1): 96. https://doi.org/10.1177/0016986217738051

[31] Mwaikinda SR, Aruguete MS. The efficacy of a student organization for STEM students. J STEM Educ. 2016; 17(3): 22-26.

[32] Kim YK, Sax LJ. Student-faculty interaction in research universities: differences by student gender, race, social class, and firstgeneration status. Res High Educ. 2009; 50: 437-459. https: //doi.org/10.1007/s11162-009-9127-x

[33] O'Keeffe P. A sense of belonging: improving student retention. Coll Stud J. 2013; (4): 605.

[34] NLN. Achieving diversity and meaningful inclusion in nursing education. National League for Nursing. 2016; 37(3): 186. 